\title{
INOVAÇÃO E PROPRIEDADE INTELECTUAL DOS 1,2,4-OXADIAZÓIS: UMA PROSPECÇÃO TECNOLÓGICA FUNDAMENTADA EM BASE DE DADOS DE PATENTES E PERIÓDICOS
}

\author{
Erick Caique Santos Costa ${ }^{a}$, Jucleiton José Rufino de Freitas ${ }^{\mathrm{b}}$ e Juliano Carlo Rufino Freitas ${ }^{\mathrm{a}, \mathrm{b}, *}$ \\ ${ }^{a}$ Centro de Educação e Saúde, Universidade Federal de Campina Grande, 58175-000 Cuité - PB, Brasil \\ bDepartamento de Química, Universidade Federal Rural de Pernambuco, 52171-900 Recife - PE, Brasil
}

Recebido em 21/11/2017; aceito em 17/01/2018; publicado na web em 08/03/2018

\begin{abstract}
INNOVATION AND INTELLECTUAL PROPERTY OF THE 1,2,4-OXADIAZOLES: A TECHNOLOGICAL SURVEY BASED ON PATENT AND PERIODICAL DATABASES. 1,2,4-Oxadiazoles are heterocyclic compounds that have a remarkable range of applications. This overview focused on investigating the potential and scientific and technological evolution of these compounds through an analysis of patent databases and scientific papers. Prospecting technology using patent databases is an important tool for mapping technologies or technological areas, allowing the identification of such things as trends and investments. The mapping of 1,2,4-oxadiazoles patents and patent applications was facilitated by using different key word from scientific papers found in the INPI, Esp@cenet, WIPO, LATIPAT databases and in the Web of Science ${ }^{\mathrm{TM}}$ database. The majority of the patent records related to the researched technology had been filed in the Esp@cenet database. A constant linear growth in the number of records of patents granted could be observed over the years, with a remarkable dominance of patents recorded in the USA (24.7\%). In addition, when the search through scientific papers was performed, the USA was also the country that had produced the largest number of publications. On the other hand, Brazil presented only two patent grant records $(0.2 \%)$ and fifty-four published papers related to the technology being researched. In summary, there is great scientific and technological interest in the 1,2,4-oxadiazoles.
\end{abstract}

Keywords: prospecting technology; heterocyclics; 1,2,4-oxadiazole.

\section{INTRODUÇÃO}

Os oxadiazóis são heterocíclicos rígidos de cinco membros que possuem em sua arquitetura molecular, além dos dois átomos de carbono, três heteroátomos (dois átomos de nitrogênio e um átomo de oxigênio). ${ }^{1}$ Eles apresentam uma baixa aromaticidade e dependendo da disposição dos heteroátomos no anel quatro isômeros podem ser sintetizados (Figura 1). ${ }^{2}$
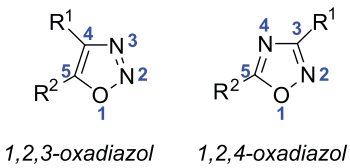

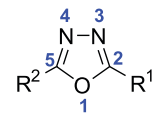

1,3,4-oxadiazol
Figura 1. Isômeros dos Oxadiazóis

Devido a semelhança dos oxadiazóis com o anel furânico, Tiemann e Krüger, em meados de 1884, nomearam esses compostos de furodiazóis. ${ }^{3,4}$ No entanto, somente após a década de 60 a química desses compostos despertou o interesse da comunidade científica e do setor industrial, devido principalmente a sua capacidade de sofrer rearranjos moleculares, ${ }^{5}$ e da sua comercialização como fármacos, a citar, Libexina e Oxolamina, ambos atuando como antitussígenos, e Irrigor, o qual apresentava propriedades de anestésico local e vasodilatador (Figura 2). ${ }^{6}$

Cabe destacar que em 2011, Carbone e colaboradores ${ }^{7}$ isolaram do molusco marinho Phidiana militaris, da família Facelinidae, os primeiros compostos oxadiazólicos de origem natural (Figura 3), os quais exibiram elevada citotoxidade in vitro contra diferentes linhagens de células tumorais de mamíferos, o que desmistificou a ideia de que a obtenção desses compostos ocorreria apenas por via sintética.

*e-mail: julianocrufino@pq.cnpq.br

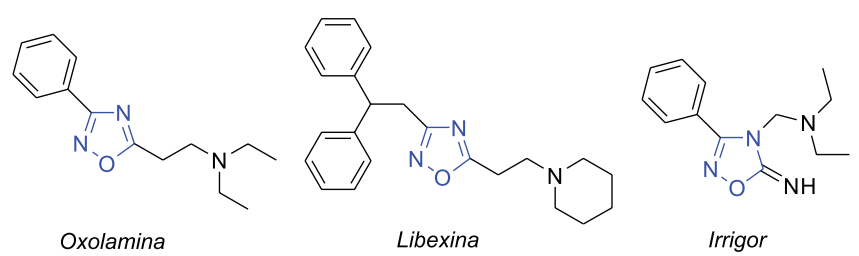

Figura 2. Estrutura dos fármacos 1,2,4-oxadiazólicos comercializados

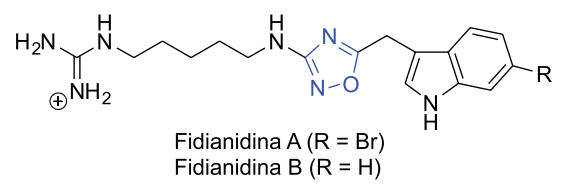

Figura 3. Compostos oxadiazólicos isolados e do molusco Phidiana miltaris

O isolamento desses produtos naturais oxadiazólicos alavancou outra vez a química desses heterocíclicos, estimulando o desenvolvimento de novas estratégias sintéticas a fim de obtê-los em elevados rendimentos e em curto tempo reacional, ${ }^{6}$ além de estimular as pesquisas referentes a suas possíveis aplicações.

Atualmente, diversas tecnologias referentes a estes compostos vêm sendo patenteadas. Estas possuem as mais distintas aplicações, como, por exemplo: a) na agricultura para o combate de fungos fitopatógenos $;^{8}$ b) no tratamento de depressão, dor, psicose, mal de Parkinson, esquizofrenia, ansiedade e transtorno do déficit de atenção com hiperatividade (ADHD) $;{ }^{9} \mathrm{c}$ ) no tratamento de diabetes do tipo $2 ;{ }^{10}$ d) como pesticidas e inseticidas; ${ }^{11-13}$ e) além de várias outras patentes com aplicações no tratamento de doenças autoimunes, bactericidas, inflamatórias, anti-hipertensivos, entre outras. ${ }^{14-17}$

Portanto, devido às potencialidades dos 1,2,4-oxadiazóis, o objetivo do trabalho foi elaborar um mapeamento científico e tecnológico por meio da análise de documentos de patentes depositados em quatro bancos de dados e dos artigos publicados na base de dados Web of 
Science $^{\mathrm{TM}}$. A pesquisa em bancos de patentes foi utilizada devido à mesma fornecer informações relevantes para o levantamento de dados permitindo realizar o mapeamento de uma tecnologia ou setor tecnológico, evidenciando seu estado atual, local ou glocal. ${ }^{18}$ Deste modo, o mapeamento permite a identificação de informações preciosas, tais como: tecnologias relevantes e seus inventores, evoluções tecnológicas, inovações, rotas tecnológicas, investimentos, tendências de mercado, produtos, parcerias, dentre outras, ${ }^{19}$ as quais reduzem as incertezas de mercado, facilitam o planejamento e a tomada de decisão e aumenta a competitividade através da capacidade de antecipação.

\section{ABORDAGEM METODOLÓGICA}

A prospecção tecnológica realizada, apesar de ter priorizado os aspectos qualitativos, também teve sua interface quantitativa, uma vez que houve necessidade de uma análise quantitativa dos dados através do uso de dados estatísticos e tabelas. ${ }^{20}$

No que se refere ao levantamento de informações que possibilitem a criação de um mapeamento, as principais ferramentas são os bancos de dados de patentes, os quais, em sua extensa variedade, dispõem-se de forma gratuita ou paga e apresentam diferenciais de qualidade, informações e ferramentas para tratamento dos dados..$^{18}$

Dentre as várias ferramentas de acesso pago, destacam-se a Delphion patent search ${ }^{\circledR}$, Dialog $^{\circledR}$, Derwent Innovations Index ${ }^{\circledR}$, Queste $^{\circledR}$, Micropatent $^{\circledR}$ e Scifinder ${ }^{\circledR}$. Estas possuem grande eficiência e rapidez no tratamento das informações recuperadas, gerando mapas, gráficos e outras análises estatísticas por um preço, geralmente, elevado. As mesmas disponibilizam de patentes do mundo todo e, em alguns casos (exemplo: Delphion patent search ${ }^{\circledR}$ e Scifinder ${ }^{\circledR}$ ), permitem o acesso gratuito em universidades via portal do Periódicos CAPES e em grandes centros de pesquisas. ${ }^{21}$

Com relação aos bancos de dados de patentes de forma inteiramente gratuita, destacam-se:

a. o INPI (Instituto Nacional da Propriedade Intelecual) - permite a busca por patentes através do sistema de pesquisa avançada, e possibilita combinar palavras-chave de título e resumo com a Classificação Internacional de Patentes (CIP), número do pedido, país depositante, número de depósito, data de depósito, data da prioridade, nome do depositante e nome do inventor ou titular. Além disso, é possível acessar patentes expiradas ou em processo de expiração. ${ }^{22}$

b. Esp@ cenet (European Patent Office - EPO) - possibilita acessar, em grande parte, o texto completo de mais de 90 milhões de documentos de patentes oriundos de vários países, sendo um dos bancos mais completos e atualizados. Permite a busca de forma simples, contudo, possui uma atualização lenta dos dados, além de apresentar divergências entre os códigos de classificação internacional de patentes quando comparados aos originais. ${ }^{23}$

c. USPTO (United States Patents Office) - permite acessar, de forma completa, patentes depositadas e patentes concedidas com campos de buscas por número, palavras-chave, entre outros. Entretanto, apresenta certas dificuldades na inserção de informações, o que diminue a possibilidade de realizar uma busca mais precisa. ${ }^{24}$

d. WIPO ou OMPI (Organização Mundial da Propriedade Intelectual) - apresenta atualização diária e é mantida pelo Patent Cooperation Treaty-PTC. Permite o acesso completo a documentos de patentes e dispõe de ferramentas estatísticas que possibilitam a elaboração de gráficos com as informações recuperadas, bem como, o acesso à coleções de diversos países como, por exemplo, o Brasil. ${ }^{25}$

e. CIPO (Canadian Intellectual Property Office) - é uma agência especial de operação do Canadá que permite a recuperação completa de documentos de patentes canadenses a partir de 1920 por meio da busca pelo número ou pelo sistema 'Booleano". ${ }^{26}$ f. JPO (Japan Patent Office) - conta com ferramentas de tradução que visam facilitar e aumentar o acesso da população ocidental e possue um sistema acelerado e de qualidade que possibilita a busca básica, por número de patente, depositante, CIP, palavras-chave, data da publicação e resumo. ${ }^{27}$

As informações contidas nesses bancos são provenientes dos sites dos seus próprios escritórios de patentes, entretanto, alguns bancos de dados gratuitos utilizam informações provenientes de outros escritórios, como é o caso do LATIPAT (Banco de Patentes Latinoamericanas), o qual é resultante de um trabalho da parceria entre a EPO, WIPO, Oficina Espanhola de Patentes e Marcas (OEPM) e outras 18 instituições de Patentes Latino-americanas. ${ }^{22}$

Logo, a prospecção tecnológica, envolvendo os 1,2,4-oxadiazóis, foi realizada a partir da pesquisa nos pedidos de patentes depositados em quatro bancos de dados, sendo eles: INPI, Esp@cenet, WIPO e LATIPAT. Estes bancos de dados foram selecionados devido a sua gratuidade, acessibilidade e confiabilidade dos dados disponíveis.

A busca de periódicos foi realizada na base de dados Web of Science $^{\mathrm{TM}}$ (Coleção Principal da Thomson Reuters Scientific) por esta disponibilizar ferramentas que permitem analisar citações, referências, índice-h, bem como, análise bibliométrica de aproximadamente 12.000 periódicos. $^{28}$

A coleta de dados foi realizada entre maio e junho de 2017, utilizando os termos: "1,2,4-oxadiazol", "1,2,4-oxadiazóis', "1,2,4-oxadiazole" e "1,2,4-oxadiazoles", os quais foram inseridos nos campos de busca avançada (Advanced Search), sendo considerados válidos os documentos de patentes e artigos que apresentassem esses termos no título ou no resumo. Foram realizadas leituras dos resumos das patentes e trabalhos encontrados e quando necessário a leitura do trabalho na íntegra.

\section{RESULTADOS E DISCUSSÃO}

De modo geral, os métodos para realização de uma prospecção tecnológica são divididos em: a) monitoramento (assessment), o qual acompanha a evolução e mudança tecnológica de forma contínua e sistemática; b) previsão (forecasting), que permite projetar novas tendências com base em informações de anterioridade. c) visão (foresight), que possibilita a antecipação de novas tecnologias através do uso de informações provenientes de especialistas..$^{29}$

O monitoramento não consiste em técnica de prospecção, contudo, é importante para definição da base da prospecção e permite o acompanhamento contínuo e sistemático da evolução tecnológica e dos indicadores de mudanças, por meio da estruturação das informações coletadas, as quais devem ser identificadas e analisadas. ${ }^{19}$

Assim, o mapeamento foi iniciado analisando o número absoluto de documentos de patentes recuperadas em cada banco de dados de acordo com a variação do termo que descreve a tecnologia pesquisada (Tabela 1)

Tabela 1. Número de documentos recuperados nos bancos de dados do INPI, Esp@cenet, WIPO e LATIPAT, utilizando os termos: "1,2,4-oxadiazol", "1,2,4-oxadiazóis", "1,2,4-oxadiazole" e "1,2,4-oxadiazoles"

\begin{tabular}{lccccc}
\hline Termo & INPI & Esp@ cenet & WIPO & LATIPAT & Total \\
\hline $1,2,4$-oxadiazol & $35^{\mathrm{a}}$ & $490^{\mathrm{b}}$ & 24 & $90^{\mathrm{a}}$ & 639 \\
1,2,4-oxadiazóis & $2^{\mathrm{a}}$ & 0 & 1 & 1 & 4 \\
1,2,4-oxadiazole & 0 & 24 & 1 & $9^{\mathrm{a}}$ & 34 \\
1,2,4-oxadiazoles & 0 & $188^{\mathrm{b}}$ & 0 & 11 & 199 \\
\hline
\end{tabular}

${ }^{\mathrm{a} D u a s}$ patente iguais entre os dados. ${ }^{\mathrm{b}}$ Cinco patente iguais entre os dados. 'Número total de patente excluindo as repetições. 
Os resultados contidos na Tabela 1 demonstram que o Esp@ cenet possui o maior número de depósitos de patentes referentes à tecnologia, com um total de 697 documentos recuperados, seguida pela LATIPAT, INPI (base de dados nacional) e a WIPO, com 109, 35 e 26 documentos recuperados, respectivamente. O elevado número de patentes recuperadas no banco de dados do Esp@cenet já era previsto, tendo em vista que, além deste conter mais de 90 milhões de documentos de patentes requeridos por diferentes países, contém os documentos depositados em outros bancos de dados como, por exemplo, patentes brasileiras depositadas apenas no INPI. ${ }^{23}$

Vale ressaltar que foram encontrados 867 registros de patentes (Tabela 1), no entanto, apesar deste número representar o total de patentes recuperadas, excluindo as repetições, este número não representa o total de invenções, haja vista que um único invento pode ser depositado em diferentes bancos de patentes como forma de assegurar aos seus inventores a exclusividade sobre os seus direitos. ${ }^{30}$

O número de depósitos de patentes relacionados ao 1,2,4-oxadiazol vem crescendo ao longo dos anos (Figura 4), sendo a primeira patente depositada em 1946 por Donald W. Kaiser, nos Estados Unidos, a qual delineava um novo método para a preparação dos 1,2,4-oxadiazóis.

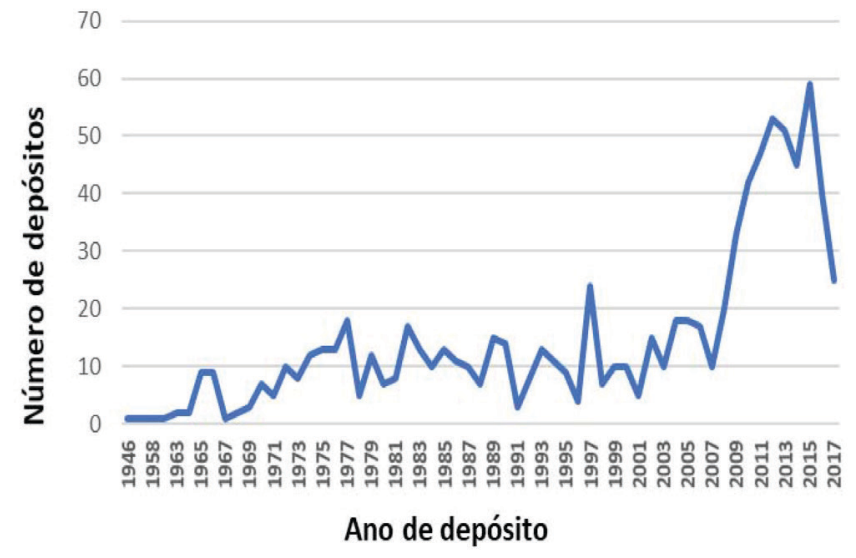

Figura 4. Evolução anual dos depósitos de patentes relacionados ao 1,2,4-oxadiazol (1946-2017)

De acordo com a Figura 4, nos últimos 10 anos, o número de depósitos de patentes cresceu significativamente, mostrando que os processos envolvendo os 1,2,4-oxadiazóis aumentaram em $102 \%$ quando comparados com o total de documentos depositados no período de 1946 a 2006. Vale destacar que no ano de 2015 houve o maior

Total de publicações por ano

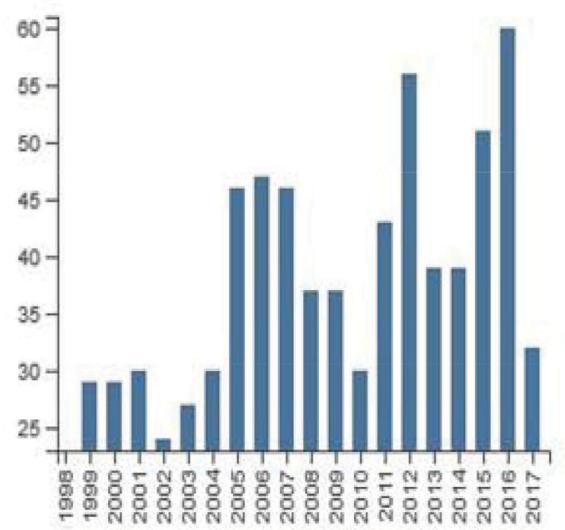

volume de depósitos de patentes, ou seja, 59 documentos, superando os anos 2012 e 2013 com 53 e 51 documentos, respectivamente. A princípio, uma das razões para o aumento abrupto dos depósitos de patentes a partir do ano de 2007 foi a descoberta de novas aplicações destes compostos tanto na química medicinal, quanto na química de materiais, seguido da descoberta, em 2011, de produtos naturais contendo o anel oxadiazólico, o que desmitificou a tese de que os 1,2,4-oxadiazóis só poderiam ser obtidos sinteticamente.

Além do crescimento no número de patentes durante os últimos anos, constatou-se, após pesquisa na base de dados Web of Science $e^{\mathrm{TM}}$ (utilizando o termo 1,2,4-oxadiazole), um crescimento constante e linear do número de publicações e de citações envolvendo a tecnologia proposta (Figura 5).

No ano de 2007 foram publicados 46 artigos, seguidos de uma ascensão do número de publicações, em 2012, com um valor de 56 trabalhos publicados e tendo seu crescimento consolidado no ano de 2016 com 60 publicações (Figura 5). Ainda com relação à pesquisa na Web of Science ${ }^{\mathrm{TM}}$ (base de dados que inclui artigos publicados desde 1945), constatou-se que o artigo mais antigo cadastrado é de 1961 publicado por Silvestrini B., o qual se intitula "Antitussive Action of Oxolamine (3-Phenyl-5- -Diethylaminoethyl1:2:4-Oxadiazole)". ${ }^{31}$ Nesse trabalho, Silvestrini descreve a ação antitussígena do oxadiazol sintetizado que mais tarde se tornou o fármaco comercial Oxolamina. ${ }^{31}$ Entretanto, o artigo com o maior número de citações foi desenvolvido nos Estados Unidos por Durner J., publicado no ano de 1998 e intitulado "Defense gene induction in tobacco by nitric oxide, cyclic GMP, and cyclic ADP-ribose"..$^{32}$ Este trabalho possui um número de 759 citações e se refere a utilização do $1 H$-(1,2,4-oxadiazol \{4,3-a\}-quinoxalina-1-ona no estudo da defesa de plantas contra microrganismo..$^{32}$ No mais, de um total de 948 artigos encontrados, constatou-se que os EUA é o país que mais publica, apresentando 165 artigos, enquanto que o Brasil tem 54 publicações, sendo isto justificado, provavelmente, devido as pesquisas envolvendo o 1,2,4-oxadiazol serem recente no Brasil, tendo em vista que o primeiro estudo publicado foi por Pereira e colaboradores em $1984 .^{33}$

Não obstante ao número de publicações, a análise realizada sobre os principais países depositantes (Figura 6) demonstra que o país detentor do maior número de depósitos de patentes, referentes à tecnologia pesquisada, é os EUA, com 215 patentes, número que representa $24,7 \%$ dos documentos recuperados. Esse número pode crescer substancialmente devido às empresas multinacionais apresentarem filiais em vários países, e 215 das patentes pesquisadas não apresentavam identificação de país depositante, havendo uma grande probabilidade de existir mais patentes depositadas pelos EUA. Em segundo e terceiro lugar encontram-se a Alemanha e o Japão, com

Total de citações por ano

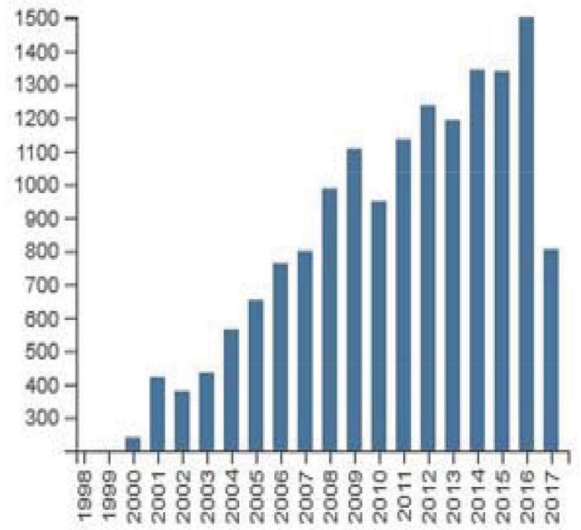

Figura 5. Número de publicações e citações sobre 1,2,4-oxadiazol no período de 1998 a $2017^{22}$ 
$13 \%$ e $10 \%$, respectivamente, não devendo ser descartada a mesma situação supracitada.

Outros países como Reino Unido (43 patentes - 4,95\%), Suíça (42 patentes - 4,84\%) e França (40 patentes - 4,61\%) são igualmente grandes investidores no desenvolvimento e inovação dessa tecnologia. Já o Brasil detém apenas duas patentes, o que representa $0,2 \%$ do total.

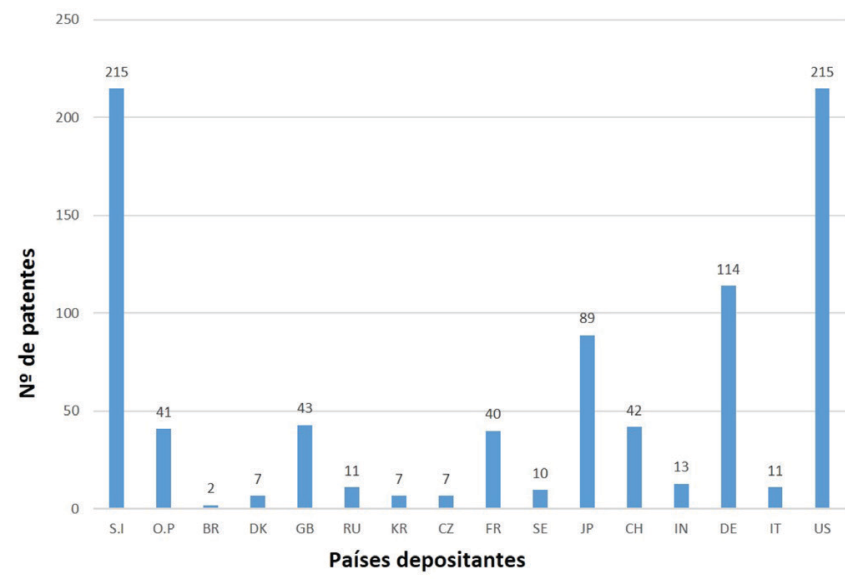

Figura 6. Distribuição dos depósitos de patentes por país de origem relacionados aos 1,2,4-oxadiazóis. Legenda: S.I: sem identificação; O.P: somatório das patentes depositadas por outros países; BR: Brasil; DK: Dinamarca; GB: Reino Unido; RU: Federação Russa; KR: República da Coréia; CZ: República Tcheca; FR: França; SE: Suécia; JP: Japão; CH: Suíça; IN: Índia; DE: Alemanha; IT: Itália; US: Estados Unidos da América.

A superioridade dos EUA quanto ao número de depósitos de patentes não surpreende, uma vez que as principais patentes referentes a esta tecnologia são decorrentes do seu setor industrial. Além disso, os EUA encontram-se no terceiro lugar do ranking mundial de competitividade e inovação, e seus investimentos em pesquisa e inovação são elevadíssimos, por exemplo, em 2013, o valor investido foi de aproximadamente 456 bilhões de dólares. ${ }^{34}$

Neste cenário, o Brasil encontra-se na $61^{\mathrm{a}}$ posição do ranking mundial de competitividade e inovação, ${ }^{35}$ e no ano de 2013 destinou $\mathrm{R} \$ 85,6$ bilhões de reais para financiamento a projetos tecnológicos. ${ }^{36}$ Adicionalmente, nos EUA, assim como em boa parte dos países da Europa, o estado estimula e até induz uma aproximação entre as empresas e universidades, gerando assim um impulso maior para as indústrias e, consequentemente, para a inovação tecnológica, fato este que, segundo Calmanovici, no Brasil, ainda está em processo de amadurecimento. ${ }^{37}$ Apesar disso, o governo brasileiro vem incentivando a competitividade das indústrias nacionais através de uma série de medidas que estimulam a busca pela inovação tecnológica, implementando políticas públicas que visam apoiar à realização de atividades de Pesquisa, Desenvolvimento e Inovação (PD\&I) e a minimização da distância entre empresas, universidades e institutos de pesquisa.

Deste modo, a lei $\mathrm{n}^{\circ} 11.196 / 05$, mais conhecida como a Lei do Bem, se caracteriza como instrumento legal para tal finalidade e engloba uma série de medidas que inclui incentivos fiscais para redução de impostos em empresas nacionais ou multinacionais que realizarem ou contratarem pesquisas e desenvolvimento de inovações tecnológicas. ${ }^{38}$ É importante ressaltar que o incentivo fiscal previsto no capítulo III da Lei do Bem é resultante da Lei n ${ }^{\circ} 10.973$ (Lei da Inovação) de 2 de dezembro de 2004, que expressa em seu Art. 28 "A União fomentará a inovação na empresa mediante a concessão de incentivos fiscais com vistas à consecução dos objetivos estabelecidos nesta Lei". ${ }^{39}$

Para se utilizar dos incentivos da Lei do Bem, as empresas não necessitam possuir atividades ligadas diretamente à PD\&I, como determina a Instrução Normativa (IN) n ${ }^{\circ} 1.187$, emitida pela Receita Federal do Brasil (RFB) em 29 de agosto de 2011, ao considerar que estas necessitam somente estar classificadas em: a) Pesquisa básica dirigida; b) Pesquisa aplicada: c) Desenvolvimento experimental; d) Tecnologia industrial básica; e) Serviços de apoio técnico, ${ }^{40}$ ampliando, assim, o espectro para acesso à estes benefícios.

De acordo com um estudo realizado em 2017 por Sanches e Barbalho, ${ }^{38}$ no período de 2009-2014, houve um crescimento de $85 \%$ ao ano no número de empresas relacionadas a Lei do Bem, no entanto, não foi observado um crescimento nos investimentos em Pesquisa e Desenvolvimento (P\&D) e sim uma queda de $-1,68 \%$ durante o mesmo período, sendo a instabilidade econômica do Brasil um dos principais motivos para este fato. Apesar das empresas que dispõe dos incentivos da Lei do Bem terem apresentado crescimento e algumas empresas perceberem o aumento na competitividade e os benefícios gerados pela parceria empresa-universidade, é perceptível a necessidade do aprimoramento de ferramentas de divulgação que esclareçam para empresas as formas de acesso e financiamentos. ${ }^{41}$

Recentemente, o Brasil avançou no desenvolvimento de políticas públicas para a inovação tecnológica com a aprovação do novo marco legal da inovação, conhecido como Código de Ciência, Tecnologia e Inovação (Lei n $\left.{ }^{\circ} 13.243 / 2016\right),{ }^{42}$ após várias discussões entre os atores do Sistema Nacional de Inovação (SNI). Este modifica pontos de leis anteriores, como a Lei da Inovação e outras oito legislações relacionadas e visa aumentar as interações entre instituições de ciência e tecnologia (ICTs), empresas e entidades privadas sem fins lucrativos, segurança jurídica e agilidade dos processos burocráticos, bem como ampliar as possibilidades de compartilhamento de recursos entre os setores público e privado que possuam atividades de PD\&I. É evidente que, devido à lei ser recente, ainda são poucas as conclusões e estudos relacionados aos seus impactos para o setor produtivo brasileiro. Contudo, para Rauner, ${ }^{43}$ a lei avançou em diversos pontos no que se refere a criação de um ambiente que estimule a inovação e promova segurança jurídica. Dentre os vários avanços, o artigo cita a reformulação do conceito de ICTs, expandindo-o à instituições privadas (pessoa jurídica de direito privado sem fins lucrativos), o que aumenta a abrangência da lei e oficializa instituições que já possuíam grande importância no cenário de inovação nacional; a ampliação das atribuições dos núcleos de inovação tecnológica (NITs), permitindo-os possuir pessonalidade jurídica, incluindo a possibilidade de serem fundações de apoio, tornando mais prática a gestão dos recursos humanos e financeiros; melhora em alguns processos burocráticos para a importação de insumos para $\mathrm{P} \& \mathrm{D}$; a regulamentação das bolsas de incentivo à atividade inovativa, entre outros.

Ainda é importante salientar que outro provável fator que contribui para os baixos índices do Brasil no ranking de competitividade e inovação é a pequena quantidade de pesquisadores com elevado nível de formação (doutorado) trabalhando na indústria, uma vez que apenas cerca de $20 \%$ dos doutores brasileiros encontram-se trabalhando nas empresas, enquanto que em países desenvolvidos este percentual é superior a $80 \% .^{44}$

As empresas com o maior número de depósitos de patentes estão representadas na Figura 7. A BAYER AG, empresa farmacêutica e química alemã, contêm 54 depósitos e, individualmente, concentra o maior número de patentes. Em seguida, destaca-se a empresa japonesa TAKEDA PHARMACEUTICAL CO, com 30 depósitos. A PTC THERAPEUTICS INC e a MERCK \& CO INC, empresas americanas de biofarmacêutica, juntas somam 46 patentes depositadas. E, por fim, as empresas britânicas GLAXO GROUP e ASTRAZANECA, ambas do setor farmacêutico, possuem juntas 43 depósitos.

Os dados de depósitos de patentes indicam que essas empresas possuem um grande interesse pela aplicação dos 1,2,4-oxadiazóis na área biológica. De fato, aproximadamente $93 \%$ das patentes 


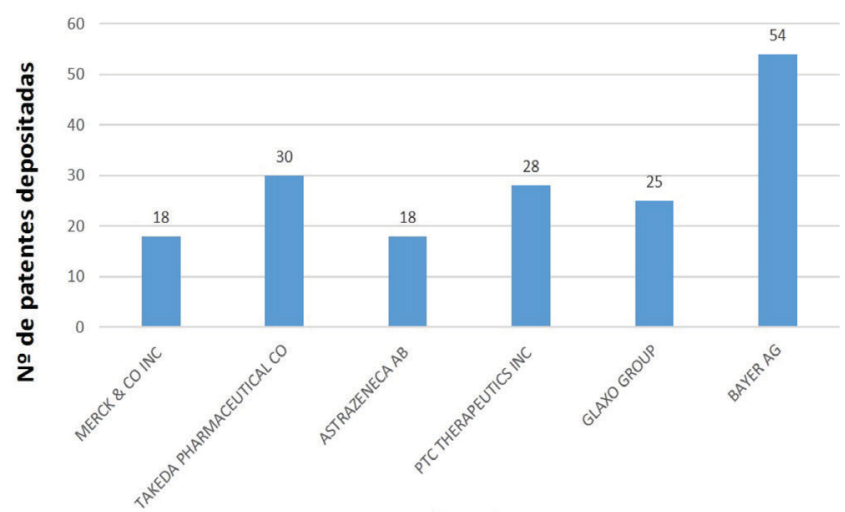

Empresas depositantes

Figura 7. Maiores empresas depositantes de patentes relacionadas aos 1,2,4-oxadiazóis

depositadas se referem a aplicações biológicas, enquanto que os 7\% restantes estão voltados para a síntese e aplicação em materiais. Por exemplo, a maior parte dos documentos depositados pela BAYER AG versam sobre o desenvolvimento e aplicação no controle e combate de pragas, fungos e parasitas, semelhantemente como as demais empresas multinacionais. Desta forma, os resultados obtidos corroboram com os dados descritos na literatura, os quais descrevem inúmeros estudos envolvendo as atividades biológicas dos 1,2,4-oxadiazóis. ${ }^{45}$

Os pedidos de patente possuem classificação de acordo com a sua área tecnológica. A maioria das CIP encontradas reforça o amplo interesse das indústrias por potenciais aplicações biológicas destes compostos. Como demonstrado na Figura 8, a CIP de maior número, comumente encontrada nas patentes, foi o C07D271/06, com 101 repetições. De modo geral, as CIP que se iniciam com C07D se referem, principalmente, aos compostos heterocíclicos de cinco membros. Em seguida, com 73 repetições, encontra-se a CIP A61K31/4245, que trata da aplicação desses compostos para fins médicos. Um fator de grande importância está atrelado às referências A61K e A01N, as quais estão relacionadas à utilização desses compostos como biocidas, repelentes ou atrativos de pestes ou reguladores do crescimento de plantas, pois enfatiza o avanço das pesquisas no controle de pragas vetores de doenças de grande impacto econômico e social em todo o mundo como, por exemplo, a dengue e a malária.

\section{CONSIDERAÇÕES FINAIS}

A prospecção tecnológica baseada em bancos de dados de patentes se mostrou uma ferramenta sistemática fundamentalmente importância para mapear a evolução e o estado atual de uma tecnologia, a fim de identificar tendências de mercado e obter informações de grande preciosidade para o direcionamento dos investimentos.

O presente estudo elaborou um mapeamento científico e tecnológico dos 1,2,4-oxadiazóis através de depósitos de patentes e artigos científicos, de modo a obter informações que auxiliem no desenvolvimento de políticas de inovação, de novas pesquisas, investimentos, bem como, na projeção de tendências tecnológicas.

De acordo com os resultados do mapeamento, apesar do primeiro relato da síntese dos 1,2,4-oxadiazóis ser datado de 1884, a primeira solicitação de depósito de patente foi registrada em 1946, sendo possível observar que a evolução das pesquisas se intensificaram a partir do ano 2007, visto que o número de pedidos de depositados cresceu abruptamente a partir desta data. A maioria dos documentos de patentes recuperados encontra-se depositada no Esp@cenet. Os americanos são os maiores detentores de patentes e de artigos publicados sobre os 1,2,4-oxadiazóis. Já o Brasil, apesar de apresentar um número expressivo de estudos sobre 1,2,4-oxadiazóis, possui

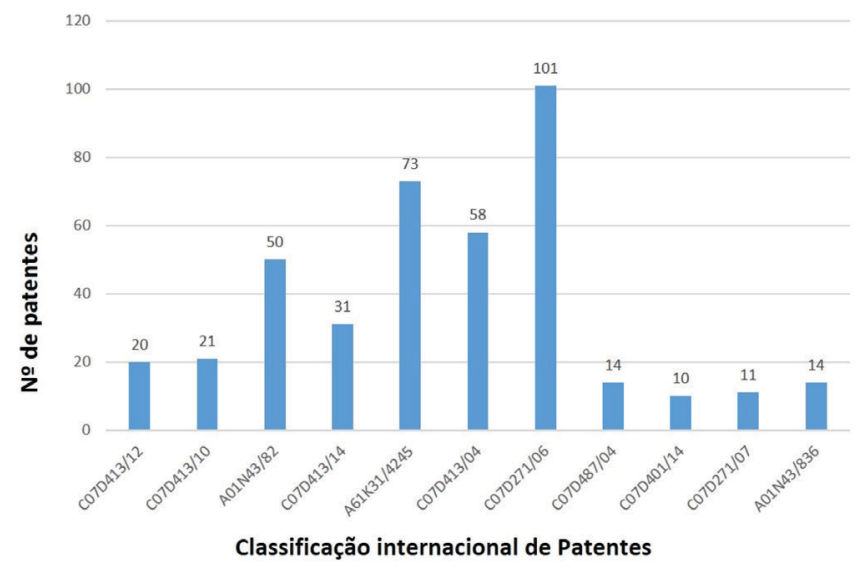

Figura 8. Classificação internacional de patentes atribuídas aos 1,2,4-oxadiazóis mais citadas. Legenda: A01N43/82: Biocidas, repelentes ou atrativos de pestes ou reguladores do crescimento de plantas contendo compostos heterocíclicos com anéis de cinco membros com três heteroátomos no anel. A01N43/836: Biocidas, repelentes ou atrativos de pestes ou reguladores do crescimento de plantas contendo compostos heterocíclicos como 1,2,4-Oxa(tia)diazóis; 1,2,4-oxa(tia)diazóis hidrogenados. A61K31/4245: Preparações medicinais contendo ingredientes ativos orgânicos (oxadiazóis). C07D413/12: Compostos heterocíclicos contendo dois ou mais heteroanéis tendo pelo menos um anel com átomos de nitrogênio e de oxigênio como os únicos heteroátomos do anel ligados por uma cadeia contendo heteroátomos como elos da cadeia. C07D413/10: Compostos heterocíclicos contendo dois ou mais heteroanéis tendo pelo menos um anel com átomos de nitrogênio e de oxigênio como os únicos heteroátomos do anel ligados por uma cadeia de carbono contendo anéis aromáticos. C07D413/04: Compostos heterocíclicos contendo dois ou mais heteroanéis tendo pelo menos um anel com átomos de nitrogênio e de oxigênio como os únicos heteroátomos do anel diretamente ligados por ligação membro a membro. C07D413/14: Compostos heterocíclicos contendo dois ou mais heteroanéis tendo pelo menos um anel com átomos de nitrogênio e de oxigênio como os únicos heteroátomos do anel e contendo três ou mais heteroanéis. C07D271/06: Compostos heterocíclicos contendo anéis de cinco membros tendo dois átomos de nitrogênio e um átomo de oxigênio como os únicos heteroátomos do anel 1,2,4-Oxadiazóis; 1,2,4-Oxadiazóis hidrogenados. C07D487/04: Compostos heterocíclicos contendo átomo de nitrogênio como os únicos heteroátomos do anel no sistema condensado, não incluídos em Sistemas condensados em orto. C07D401/14: Compostos heterocíclicos contendo dois ou mais heteroanéis tendo átomos de nitrogênio como os únicos heteroátomos do anel, pelo menos um dos anéis sendo de um de seis membros com apenas um átomo de nitrogênio contendo três ou mais heteroanéis. C07D271/07: Compostos heterocíclicos contendo anéis de cinco membros tendo dois átomos de nitrogênio e um átomo de oxigênio como os únicos heteroátomos do anel com átomos de oxigênio, enxofre ou nitrogênio diretamente ligados a átomos de carbono do anel, os átomos de nitrogênio não fazendo parte de um radical nitrado.

apenas duas patentes registradas. Deste modo, o estudo evidência a relevância dos 1,2,4-oxadiazóis e fornece informações que podem estimular estudos mais profundos deste setor tecnológico a fim de propiciar suporte para inovação, desenvolvimento científico e tecnológico, bem como a identificação de tendências de mercado e elaboração novas estratégias de investimentos e aprimoramento de políticas públicas de PD\&I.

\section{AGRADECIMENTOS}

Os autores agradecem às agências de fomento CNPq (447361/2014-7), PRONEM/FACEPE (APQ-0476-1.06/14) pelo suporte financeiro e CAPES pelas bolsas concedidas. 


\section{REFERÊNCIAS}

1. Jain, S. K.; Nadan, J.; World J. Pharm. Pharm. Sci. 2014, 3, 762.

2. Regueira, J. L. L. F.; Freitas, J. J. R.; Filho, J. R. F.; Quim. Nova 2016, 39, 1019.

3. Tiemann, F.; Krüger, P.; Ber. Dtsch. Chem. Ges. 1884, 17, 1685.

4. Bora, R. O.; Dar, B.; Pradhan, V.; Farooqui, M.; Mini-Rev. Med. Chem. 2014, 14, 355.

5. Pace, A.; Pierro, P.; Org. Biomol. Chem. 2009, 7, 4337.

6. Freitas, J. J. R.; Silva, E. E.; Regueira, J. L. 1. F.; Andrade, S. A.; Cavalcante, P. M. M.; de Oliveira, R. N.; Freitas Filho, J. R.; Rev. Virtual Quim. 2012, 4, 670 .

7. Carbone, M.; Li, Y.; Irace, C.; Mollo, E.; Castelluccio, F.; di Pascale, A.; Cimino, G.; Santamaria, R.; Guo, Y.-W; Gavagnin, M.; Org. Lett. 2011, $13,2516$.

8. Wieja, A.; Winter, C.; Rosenbaum, C.; Kremzow-graw, D.; Roehl, F.; Rheinheimer, J.; Poonoth, M.; Terteryan, V.; Haden, E.; Escribano, C. A.; Achenbach, J. H.; Mentzel, T. Wiebe C.; US pat 2017144980 (A1), 2017.

9. Ratni, H.; Vifian, W.; Nettekoven, M.; BR pat 1120130002530 A2, 2016.

10. Jones, R. M; Buzard, D. J.; Kawasaki, A. M.; Lopez, L. A.; Moody J. V.; Lars, T.; Brett, U.; CN pat 101981030 (A), 2011.

11. Gutman, A. D.; US pat 4134985 (A), 1979.

12. King, W. F.; Wheeler, R. E.; US pat 4308260 (A), 1981.

13. Wood, J.; CH pat 519299 (A), 1972.

14. Eldred, C. D.; Heer, J. P.; Heightman, T. D. Skidmore, J.; Wang, H.; EP pat 2271643 (A1), 2011.

15. Narayanan, V. L.; Gadebusch, H. H; Haugwitz, R. D.; US pat 4065563 (A), 1977

16. Rainer, A.; Frederic, Z.; PT pat 1981858 (E), 2010.

17. Dimsdale, M. J.; US pat 4242352 (A), 1980.

18. Speziali, M. G.; Sinisterra, R. D.; Quim. Nova 2015, 38, 1132.

19. Amparo, K. K. Dos S.; Ribeiro, M, C, O.; Guarieiro, L. L. N.; Perspectivas em Ciência da Informação 2012, 17, 195.

20. Bogdan, R. C.; Biklen, S. K.; Investigação qualitativa em educação, Porto: Porto, 1994, 167p.

21. http://www.periodicos.capes.gov.br, acessada em Fevereiro 2018.

22. http://www.inpi.gov.br, acessada em Fevereiro 2018.

23. http://www.espacenet.com, acessada em Fevereiro 2018.

24. http://www.uspto.gov, acessada em Fevereiro 2018.

25. http://www.wipo.int, acessada em Fevereiro 2018.

26. http://patents1.ic.gc.ca, acessada em Fevereiro 2018.

27. http://www.jpo.go.jp, acessada em Fevereiro 2018.

28. http://www.webofknowledge.com, acessada em Fevereiro 2018.

29. Caruso, L. A. C.; Tigre, P. B.; Modelo SENAI de prospecção: documento
Metodológico, $1^{\mathrm{a}}$ ed., CINTERFOR/OIT: Montevideo, 2004.

30. Mendonça, T. A.; Dantas; E. A.; Gouvea, A. A. L.; Oliveira, R. S.; Alves, A. R. C.; Padilha, F. F.; Machado, B. A. S.; Rev. Virtual Quim. 2016, 8, 1094.

31. Silvestrini, B.; Biochem. Pharmacol. 1961, 8160.

32. Durner J.; Wendehenne, D.; Klessig, D. F.; Proc. Natl. Acad. Sci. U. S. A. 1998, 95, 10328 .

33. Pereira, A. M. G.; Brinn, I. M.; Srivastava, R. M.; Martin, 1.; J. Chem. Soc., Faraday Trans. 2 1984, 80, 763.

34. https://www.nsf.gov/statistics/2016/nsb20161/\#/singleind/11/T, acessada em Fevereiro 2018.

35. World Competitiveness Yearbook, do international institute for Management development (iMd), 2017. http://www.imd.org/research/ publications/wcy/index.cfm, acessada em Fevereiro 2018.

36. http://www.investe.sp.gov.br/noticia/investimento-em-c-t-no-brasilcresceu-nos-ultimos-anos-e-representa-parcela-maior-do-pib/, acessada em Fevereiro de 2018.

37. Calmanovici, C. E.; Revista USP 2011, 190.

38. Sanches, E. A.; Barbalho, S. C. M. Lei do Bem no Brasil: evolução histórica, efeitos e o futuro, 2017. http://propesq.ufsc.br/artigo-explicaos-incentivos-fiscais-da-lei-do-bem/, acessada em Fevereiro 2018.

39. Brasil. Ministério da Ciência, Tecnologia e Inovação - MCTI. Relatório anual da utilização dos incentivos fiscais, Ano base 2010, 2011. http:// inei.org.br/inovateca/mct-relatorio-anual-do-uso-de-incentivos-fiscais, acessada em Fevereiro 2018.

40. Lopes, I. F.; Beuren, I. M.; Perspectivas em Gestão \& Conhecimento 2016, 6, 109.

41. Bueno, A.; Torkomian, A. L. V.; Revista de Administração e Inovação 2014, 11, 135.

42. Brasil. Lei ${ }^{\circ} 13.243$, de 11 de Janeiro de 2016. Dispõe sobre o estímulo ao desenvolvimento científico, à pesquisa, à capacitação científica e tecnológica e altera a Lei no 10.973, de 2 de dezembro de 2004, a Lei no 6.815, de 19 de agosto de 1980, a Lei no 8.666, de 21 de junho de 1993, a Lei no 12.462, de 4 de agosto de 2011, a Lei no 8.745, de 9 de dezembro de 1993, a Lei no 8.958, de 20 de dezembro de 1994, a Lei no 8.010, de 29 de março de 1990, a Lei no 8.032, de 12 de abril de 1990, e a Lei no 12.772, de 28 de dezembro de 2012, nos termos da Emenda Constitucional no 85, de 26 de fevereiro de 2015. Diário Oficial da União, Brasília, 2016a. http://www.planalto.gov.br/ccivil_03/_ato20152018/2016/lei/113243.htm, acessada em Fevereiro 2018.

43. Rauen, C. V.; O novo marco legal da inovação no Brasil: o que muda na relação ICT-EMPRESA?, Radar 2016, 43.

44. Cota, M. M. G.; Gomes, J. P. S.; Lunardi, L. M.; Gomes, C. de Andrade.; Salles, A. M.; Di Blasi, G.; Soares, E. E.; Ind. Biotechnol. 2016, 12, 58. 45. Cunha, F. S.; de Aguiar, A. P.; Rev. Virtual Quim. 2015, 7, 2509. 